\title{
Analysis on the Reasons of Academic Burnout Among Chinese Adolescents
}

\author{
Yanting $\mathrm{Ma}^{1, *}$ \\ ${ }^{1}$ University College London, Gower Street, London WC1E 6BT, UK \\ *Corresponding author. Email: yanting.ma.19@ucl.ac.uk
}

\begin{abstract}
Academic burnout is investigated by scholars and has been found to have negative influences on students' mental health. This paper is going to outline the possible reasons for academic burnout using literature review from both internal and external perspectives. Internal reasons include: the effect of perfectionism, individual mindfulness and achievement goals hold by the students during their academic life. External reasons are parenting styles and the school environment. This paper concludes with suggestions to prevent academic burnout for future researchers and educators.
\end{abstract}

Keywords: Academic burnout, Adolescent, China, Impacts of academic burnout, Reasons for academic burnout.

\section{INTRODUCTION}

School is an important developmental context for adolescents and has been criticized for developing harmful psychological disorders such as academic burnout [1]. Academic burnout is characterized by emotional exhaustion, cynicism and low efficacy [2]. Burnout has been studied in the workplace and organization intensely since it has been regarded as a work-related disorder. Still, the reasons on students are revealed recently and call more attention to this specific issue. From a psychological perspective, although students are not having a job or be employed, their daily activities in a school setting can be considered as work [1]. Academic burnout is displayed among students during the learning process due to excessive course stress, course load or other psychological factors [2]. Hence, this paper aims to analyze the reasons for academic burnout, specifically focus on Chinese adolescents. The overview on academic burnout is expected to raise public awareness of such issues and call for future research on this rising issue.

\section{REASONS OF ACADEMIC BURNOUT AMONG ADOLESCENTS}

\subsection{Internal Factors}

Academic burnout can be categorized into internal and external factors. Internal burnout is a personal factor that may trigger burnout and how the impact of academic burnout varies among adolescents due to individual differences.

\subsubsection{Perfectionism}

Perfectionism has been proved may trigger academic burnout, but only the exceed standards on self would lead to such result [3], [4]. Perfectionism is a personality trait that an individual will strive to achieve flawlessness in everything not limited to work or study [5]. It was examined in various studies that perfectionism has led to complex and diverse psychological functioning, but different perfectionism forms may lead to a contrasting outcome. Research suggests that only perfectionism concern is correlated with burnout, whereas perfectionism striving is linked to engagement [6]. To be specific, perfectionistic concerns have displayed a more significant negative relationship with burnout than perfectionist strivings. 
Perfectionism concerns contain self-evaluation on adverse outcomes, whereas perfectionism striving is how individuals set high standards for themselves. Similarly, the study by Luo et al. [4] found that only maladaptive perfectionism is related to school burnout, but adaptive perfectionism is not. Individuals with maladaptive perfectionism tend to doubt their ability and constantly believe the task is too challenging for them. Furthermore, self-esteem has displayed an essential role in mediating perfectionism and academic burnout [4]. The individual with low self-esteem shows more fear of failure, which is also the core feature of maladaptive perfectionism. Therefore, academic burnout is more correlated with the negative ideas on self because of perfectionism.

\subsubsection{Mindfulness}

As perfectionism may impact how individual thinking about themselves, another internal factor of academic burnout is mindfulness which is similar to how personal process information and apply to themselves. Mindfulness is the ability to combine experiences and actions of the present without judgment and these experiences' involvement [7]. Dispositional mindfulness is linked to the general tendency of an individual to attend the present event non-judgmentally. It is found out that dispositional mindfulness, especially those related to traumatized events, has negatively correlated with academic burnout. The study of $\mathrm{Xu}$ and colleagues [8] has found that students with high levels of dispositional mindfulness suffered less academic burnout after the Yancheng tornado in 2016. It was suggested that the negative posttraumatic beliefs mediated the relationship between dispositional mindfulness and academic burnout. To explain this, if students endorse negative posttraumatic thoughts, those with dispositional mindfulness will suffer less academic burnout. Therefore, dispositional mindfulness has predicting academic burnout especially for those who have carried posttraumatic beliefs. Hence future studies have to include the impact of traumatized events into assessing adolescents' mental well-being.

\subsubsection{Motivation \& Achievement Goals}

Different from the two former ideas, it has also been proved that motivation or achievement goals of adolescents may lead to academic burnout. Achievement goals play essential roles in the reasons for persons' motive towards goals [9]. In a schooled environment, students perform different types of achievement goals towards their study, which determines students' evaluation of their situations and behaviour [10]. Hence, this will influence their experience on learning and studying outcome. China is a particular case by having most students holding high multiple goals in their academic years [11]. This is because the highly competitive and cruel studying environment has led to a greater range of Chinese adolescents' goals than adolescents in other countries. And such an environment has also been criticized being the major factor for decreasing psychological wellbeing. Arguably, high multiple goals manipulated from the intense studying environment seem to exert fewer negative influences on adolescents [11]. Although students tended to show more anxiety towards examinations, they showed less cynicism and high academic self-efficacy. The study by Liu et al. [11] combined the achievement approaches and found that high performance-avoidance goals are critical in leading to emotional exhaustion. Therefore, performance-avoidance achievement goals would lead to adverse psychological outcomes, which may be the potential reason for Chinese students to experience academic burnout.

\subsection{External Factors}

Apart from personal reasons, academic burnout may also result from external factors. This includes how the environment, such as parenting practices and school affect adolescents.

\subsubsection{Parenting Styles}

Various studies have argued about the relation between parenting practices and academic burnout. Studies highlighted that parenting styles would affect adolescents' academic achievement [12], but studies have contrasting ideas on parenting practices' impacts. It was highlighted that a negative parenting style is positively correlated with students' academic burnout [3], [13]. A negative parenting style is characterized by features like rejection and excessive protection [3]. Students who suffered such a negative parenting styles would score high in the Academic Burnout Survey. Furthermore, it is also found that a negative parenting style may lead to the formation of an opposing personality [3]. As students constantly affected by negative parenting style, they may demonstrate fear to their parents or fail to solve problems independently, which makes them more likely to perform similar behaviour to schoolwork. 
Thus, a negative parenting style may result in academic burnout. However, the study is debatable about the categorization of negative parenting style. Although studies designed different styles of parenting and have differentiated parenting forms, it is not holistic to conclude the parenting styles among the general population. According to various studies, authoritative parenting is the most effective style in improving academic achievement. But according to Zhu and colleagues [13], authoritative parenting [give the children some freedom to choose but carry expectations on them] only predicted intellectual engagement but less academic burnout in adolescent. Therefore, academic burnout may have resulted from rejection and excessive protection from parents. Still, it is unclear whether there is a long-term parenting style that can lead to academic burnout.

\subsubsection{School Environment}

Apart from parenting influence, the school environment is also an essential external factor in the development of academic burnout. Students' perception of classroom structure impacts academic burnout [14]. Students who perceive a lower level of classroom setting are more likely to adopt burnout experience. If the classroom structure meets students' expectations and directions, as well as letting students have a sense of control, students less likely to experience academic burnout. It is also worth mentioning that academic coping plays an essential part in the relationship between students' perceptions of classroom structure. Coping is referred to as the 'cognitive and behavioural efforts made to manage demand' [14]. Engaging and seeking supports are the two copings that allow students to perceive higher classroom structure. At the same time, disengagement is more likely to report a lower level of classroom structure. Furthermore, the school environment also consists of peer relations which will influence an individual's academic burnout. In Wang and colleagues' study [15], academic burnout was the critical psychological process between negative school gossip and suicide intention. Rumors may reduce an individual's sense of belongings, thus increased suicide intention. This relationship is partial mediated by academic burnout since thwarted belongingness will lead to burnout. It is also found that peer supports influence students' burnout experiences indirectly through their use of coping strategies, but this is highly depending on students' perception of supports [14].

\section{POSSIBLE METHODS TO AVOID ACADEMIC BURNOUT}

\subsection{Internal Method}

Perfectionism is a personality trait, and it can be hard to overturn it through psychological methods. While developing dispositional mindfulness can effectively prevent academic burnout and can be put into clinical practice [7]. It is also essential for educators to pay extra attention to adolescents who have gone through traumatic events. They should be taken care of mental recovery, and school should set a more positive and encouraging environment.

\subsection{External Method}

It is also crucial for educators to notice the influence of school environments on academic burnout. Although it is hard to justify an effective parenting style that will prevent the development of academic burnout, parents should try to reduce rejection and over-protection to their children [3]. Furthermore, with the results by Wang et al. [9], schools need to pay attention to public bullying and relational bullying, such as negative gossip. Schools should build a harmonious and friendly atmosphere among students. Therefore, and interpersonal communication skills should also be promoted as well as psychological education.

Chinese students tend to carry multiple goals during their academic life. Thus, improving Chinese adolescents' mastery and oriented learning approach instead of multiple goals may produce a positive learning outcome [11]. Therefore, parents and teachers should provide students with support that respects their interest and satisfy their psychological needs and emphasize mastery approach.

\section{CONCLUSION}

To conclude, the reasons academic burnout can be categorized into internal and external factors. Internal reasons are the maladaptive effect of perfectionism, dispositional mindfulness after traumatized events and performance-avoidance achievement goals holding by the students. External reasons include rejection and excessive protection from parents and the school environment. It is crucial for future researchers and educators to examine the reasons for academic burnout in a holistic way by including both internal and external factors. 


\section{AUTHORS' CONTRIBUTIONS}

This paper is independently completed by Yanting Ma.

\section{ACKNOWLEDGMENTS}

I would like to show my gratitude to all my teachers who have provided insightful ideas and great support to me and my work.

\section{REFERENCES}

[1] Salmela-Aro, K., Kiuru, N., Pietikäinen, M., \& Jokela, J. (2008). Does School Matter?. European Psychologist, 13(1), 12-23. https://doi.org/10.1027/1016-9040.13.1.12

[2] Lin, S., \& Huang, Y. (2013). Life stress and academic burnout. Active Learning in Higher Education, $\quad 15(1)$ 77-90. https://doi.org/10.1177/1469787413514651

[3] Ding, X., Zhibing, Z., \& Ge, G. (2019). The Study on the Relationship Among Parenting Style, Negative Perfectionism and Academic Burnout of College Students. 2019 10Th International Conference On Information Technology In Medicine And Education ((ITME)).

https://doi.org/10.1109/itme.2019.00061

[4] Luo, Y., Wang, Z., Zhang, H., Chen, A., \& Quan, S. (2016). The effect of perfectionism on school burnout among adolescence: The mediator of self-esteem and coping style. Personality And Individual Differences, 88 , 202-208. https://doi.org/10.1016/j.paid.2015.08.056

[5] Curran, T., Hill, A., Madigan, D., \& Stornæs, A. (2020). A test of social learning and parent socialization perspectives on the development of perfectionism. Personality and Individual Differences, $160, \quad 109925$. https://doi.org/10.1016/j.paid.2020.109925

[6] Hill, A., \& Curran, T. (2016). Multidimensional Perfectionism and Burnout. Personality and Social Psychology Review, 20(3), 269-288. https://doi.org/10.1177/1088868315596286

[7] Yuan, G., Xu, W., Liu, Z., Liu, C., Li, W., \& An, Y. 2018. Dispositional Mindfulness, Posttraumatic Stress Disorder Symptoms and Academic Burnout in Chinese Adolescents
Following a Tornado: The Role of Mediation through Regulatory Emotional Self-Efficacy. Journal Of Aggression, Maltreatment \& Trauma, $\quad 27 \quad$ (5), $\quad 487-504$. https://doi.org/10.1080/10926771.2018.14332 58

[8] Xu, W., An, Y., Ding, X., Yuan, G., Zhuang, Y., \& Goh, P. 2017. Dispositional mindfulness, negative posttraumatic beliefs, and academic burnout among adolescents following the 2016 Yancheng Tornado. Personality And Individual Differences, 116, 405-409. https://doi.org/10.1016/j.paid.2017.05.029

[9] Elliot, A., \& Church, M. (1997). A hierarchical model of approach and avoidance achievement motivation. Journal Of Personality And Social Psychology, 72 (1), 218-232. https://doi.org/10.1037/00223514.72.1.218

[10] Daumiller, M., \& Dresel, M. (2020). Researchers' achievement goals: Prevalence, structure, and associations with job burnout/engagement and professional learning. Contemporary Educational Psychology, 61, 101843. https://doi.org/10.1016/j.cedpsych.2020.10184 3

[11] Liu, H., Yao, M., \& Li, J. (2020). Chinese adolescents' achievement goal profiles and their relation to academic burnout, learning engagement, and test anxiety. Learning and Individual Differences, 83-84, 101945. https://doi.org/10.1016/j.lindif.2020.101945

[12] Masud, H., Thurasamy, R., \& Ahmad, M. (2014). Parenting styles and academic achievement of young adolescents: A systematic literature review. Quality \& Quantity, 49(6), 2411-2433. https://doi.org/10.1007/s11135-014-0120-X

[13] Zhu, Q., Cheong, Y., Wang, C., \& Tong, J. (2021). The impact of maternal and paternal parenting styles and parental involvement on Chinese adolescents' academic engagement and burnout. Current Psychology. https://doi.org/10.1007/s12144-021-01611-z

[14] Shih, S. 2015. The relationships among Taiwanese adolescents' perceived classroom environment, academic coping, and burnout. School Psychology Quarterly, 30 (2), 307-320. https://doi.org/10.1037/spq0000093 
[15] Wang, Q., Hu, W., Ouyang, X., Chen, H., Qi, Y., \& Jiang, Y. 2020. The relationship between negative school gossip and suicide intention in Chinese junior high school students: The mediating effect of academic burnout and gender difference. Children and Youth Services Review, 117, 105272. https://doi.org/10.1016/j.childyouth.2020.1052 72 